LINGUA, Vol. 14, No. 2, September 2017

p ISSN: 1979 9411; e ISSN: 2442 238X

Http://lingua.pusatbahasa.or.id; Email: presslingua@gmail.com

Center of Language and Culture Studies, Surakarta, Indonesia

Nasution, Suti H, Sari. 2017. Proses Morfofonemik dalam Bahasa Jepang. Lingua (2017), 14(2): 259 266.

\title{
PROSES MORFOFONEMIK DALAM BAHASA JEPANG
}

\author{
Sari Suti H. Nasution \\ Pascasarjana Program Studi Linguistik \\ Universitas Sumatera Utara \\ Jl. A. Hakim No1, Kampus USU, Medan 20155
}

Email: $\underline{\text { sari_suti@yahoo.com }}$

\begin{abstract}
This study examines process of morphophonemics in Japanese language. This qualitative study used content analysis as the research design approaching the analysis in qualitative approach. Corpus of this study included words, phrases, sentences and discourse obtained from the two Japanese texts for children: minna no nihongo and Japenese films. Data were analyzed using interactive model: reduction, display, verification and conclusion drawing implementing morphophonemics theory of Koizumi. The study revealed that morphophonemics as a process order between morphology and phonology of a language occured in the Japanese texts for children stiries and the films: including fuka, sakujo, chikau, zero setsuji.
\end{abstract}

Keywords: morphophonemics, Japanese language, content analysis.

Morfologi dalam bahasa Jepang disebut dengan keitairon. Kietairon wa gokei no bunseki ga chusin to naru. 'Morfologi adalah suatu bidang ilmu yang meneliti pembentukan kata' (Koizumi, 1993:89). Pembentukan kata mencakup bentuk kata, fungsi dan pengaruh perubahan-perubahan bentuk kata terhadap golongan dan arti kata baik secara gramatik maupun semantik. Morfem adalah satuan morfologi terkecil dari bahasa dan tidak dapat dipecah menjadi bentuk yang lebih kecil karena dapat merubah makna. Morfem terdiri dari morfem terikat dan morfem bebas. Morfem terikat adalah morfem yang tidak dapat berdiri sendiri tanpa adanya morfem yang lain seperti awalan me-, akhiran -kan dan lain-lain yang termasuk ke dalam afiks. Sedangkan morfem bebas adalah bentuk linguistik terkecil yang dapat berdiri sendiri seperti baju, tidur, makan. Dalam bahasa Jepang, ada kata yang hanya terdiri dari satu suku kata seperti $k a$ 'nyamuk' dan wa 'gelang/ring'. Ini pun merupakan satu kata morfem, tetapi kata kawa 'sungai'meskipun terdiri dari dua silabel, yaitu ka dan wa, tetap merupakan satu morfem, karena kadan wa pada kata \{kawa\} tidak mengandung suatu makna.

Proses morfofonemik adalah cabang linguistik yang mengkaji dan mengklasifikasikan morfem yang muncul akibat pengaruh dari faktor-faktor fonologis atau faktor-faktor gramatikal yang berperan dalam pemunculan fonem. Morfofonemik menunjukkan adanya hubungan antara morfem dan fonem dan bagaimana hubungan morfem dan fonem itu bermunculan adalah karena adanya proses. Perubahan bentuk sebuah morfem berdasarkan bunyi atau perubahan yang menyangkut hubungan antara morfem dan fonem, disebut perubahan-perubahan morfofonemik. Perubahan-perubahan morfofonemik yang terjadi pada umumnya ditujukan untuk mempermudah dan 
LINGUA, Vol. 14, No. 2, September 2017

p ISSN: 1979 9411; e ISSN: 2442 238X

Http://lingua.pusatbahasa.or.id; Email: presslingua@gmail.com

Center of Language and Culture Studies, Surakarta, Indonesia

Nasution, Suti H, Sari. 2017. Proses Morfofonemik dalam Bahasa Jepang.

Lingua (2017), 14(2): 259 266.

memperlancar pengucapan. Dalam bahasa Jepang juga banyak kata ataupun morfem yang muncul akibat proses ini. Misalnya:

$\begin{array}{ll}\text { Kuniguni } & \text { 'negara-negara' } \\ \text { Hitobito } & \text { 'orang-orang' } \\ \text { Shimbun } & \text { 'koran' }\end{array}$

Ketiga kata di atas, jika diperhatikan dan dibaca oleh semua orang merupakan hal yang biasa dan tidak tahu bahwa sebenarnya kata-kata tersebut mengalami yang namanya proses morfofonemik. Bagi pembelajar bahasa Jepang khususnya mereka tidak paham atau tidak tahu kalau kata-kata tersebut berbeda dari aturan bahasa Jepang yang sebenarnya. Hal ini dikarenakan mereka tidak atau belum belajar tentang morfologi bahasa Jepang.

Pembelajar bahasa Jepang yang belajar bahasa Jepang sebagai bagian dari kegiatan tambahan untuk menambah pengetahuan lain di luar pembelajaran umum maka tidak akan pernah kenal dengan yang namanya proses morfofonemik karena mereka belajar bahasa Jepang dalam percakapan sehari-hari ataupun untuk istilah-istilah umum lainnya. Sementara bagi pembelajar bahasa Jepang di tingkat sarjana mereka perlu dan harus tahu apa yang dimaksud dengan proses morfofonemik bahasa Jepang karena hal ini merupakan bagian penting dari morfologi sebagai cabang linguistik. Oleh karena itu, penulis akan mengkaji proses morfofonemik dalam bahasa Jepang dan apa saja yang menjadi bagian dari proses tersebut. Sehingga kajian ini nantinya diharapkan dapat menjadi referensi tambahan dalam penelitian yang terkait bahasa Jepang khususnya kajian morfologi.

Penulis memilih judul ini karena setelah penelusuran yang dilakukan oleh penulis belum ada penelitian yang membahas proses morfofonemik bahasa Jepang secara khusus. Secara konsep proses morfofonemik adalah sebuah proses mengelompokkan morfem yang muncul akibat pengaruh dari faktor-faktor fonologis atau faktor-faktor gramatikal yang berperan dalam pemunculan fonem. Berdasarkan teori maka proses morfofonemik termasuk ke dalam ranah morfologi dan fonologi. Morfologi adalah ilmu yang mengkaji tentang kata dan pembentukannya. Koizumi (1993:89) mengatakan: Kietairon wa gokei no bunseki ga chusin to naru. 'Morfologi adalah suatu bidang ilmu yang meneliti pembentukan kata'. Fonologi diartikan sebagai kajian bahasa yang mempelajari tentang bunyi-bunyi bahasa yang diproduksi oleh alat ucap manusia. Jadi, morfofonemik atau morfofonologi adalah pengelompokkan morfem yang muncul akibat pengaruh morfologis dan fonologis.

\section{METODE}

Dalam kajian ini digunakan jenis penelittian yang dilakukan adalah penelitian kualitatif. Dengan content analysis sebagai design penelitian. Sebagai penelitian kualitatif, data yang digunakan berupa kata, frasa, kalimat dan konteks. Adapun content analysis maksudnya penelitian memfokuskan pada dokumen berupa buku-buku dan teks tertulis mengenai penggunaan morfologi bahasa Jepang sebagai sumber kajian. 
LINGUA, Vol. 14, No. 2, September 2017

p ISSN: 1979 9411; e ISSN: 2442 238X

Http://lingua.pusatbahasa.or.id; Email: presslingua@gmail.com

Center of Language and Culture Studies, Surakarta, Indonesia

Nasution, Suti H, Sari. 2017. Proses Morfofonemik dalam Bahasa Jepang.

Lingua (2017), 14(2): 259 266.

Metode analisis data yang dipakai adalah metode analisis data kualitatif Miles dan Huberman (1994). Miles dan Hubermen mengemukakan bahwa akifitas dalam analisis data kualitatif dilakukan secara interaktif dan berlangsung secara terus menerus sampai tuntas, sehingga datanya jenuh. Ukuran kejenuhan data ditandai dengan tidak diperolehnya lagi data atau informasi baru. Akifitas dalam analisis meliputi pengumpulan data, kondensasi data, penyajian data serta verifikasi dan penarikan kesimpulan.

Sumber data penelitian diambil dari buku cerita anak-anak bahasa Jepang, minna no nihongo dan data lisan yang didapat dari film bahasa Jepang. Data penelitian berupa semua morfem dan kata yang mengalami proses morfofonemik. Data dikumpulkan dengan metode observasi dengan teknik simak baca catat. Data sekunder penelitian ialah wawancara dengan pembaca buku teks berbahasa Jepang tersebut dan penonton film berbahasa Jepang yang diputar oleh peneliti.

Data dianalisis menggunakan kerangka analisis interaktif dari Miles dan Hubermen (1994) yang menyajikan tiga langkah analisis: reduksi data, display, dan verifikasi-konklusi. Pada tahap reduksi, peneliti memilah dan memilih kata, frase, dan kalimat yang memiki unsur-unsur morfologi bahasa Jepang. Data yang dianalisis diambil dari data tertulis dan data lisan. Data-data yang mengandung unsur morfem bahasa Jepang tersebut kemudian dikelompokkan dan dikatagorisasikan menurut jenis morfemnya.

Tahap display (penyajian) peneliti melakukan pengelompokkan jenis morfem menurut katagorinya dalam satu paparan berupa matriks dan tabel. Morfem dikelompokkan ke dalam morfem terikat, morfem bebas, afiksasi, dan pembentukan kelas kata menjadi noun, verb, adjective, adverbs serta imbuhan yang sering muncul untuk membentuk makna kata baru.

Pada tahap verifikasi dan konclusi, peneliti mengadakan uji keabsahan data. Pada tahap ini, selain peneliti mengecek kebenaran penyajian agar diperoleh simpulan yang benar, peneliti juga melakukan pengecekan keabsahan data melalui teknik triangulasi sumber data. Triangulasi data maksudnya pengumpulan satu jenis data melalui beberapa jenis sumber. Data-data yang sudah di-display dicek kebenarannya dengan sumber data tulisan dan lisan yang diambil dari buku dan film. Setelah itu, data dari kedua sumber tersebut dicocokkan lagi. Jika terdapat kekeliruan dari salah satu sumber, peneliti melakukan pengecekan ulang sampai diperoleh simpulan bahwa data tertentu dinyatakan benar. Setelah triangulasi sumber data, peneliti juga melakukan triangulasi teori. Peneliti melakukan pengecekan teori morfologi dalam bahasa Jepang dan teori morfologi bahasa Inggris serta bahasa Indonesia. Triangulasi ini bertujuan untuk memastikan bahwa data yang sudah penelisi verifikasi dan simpulkan, secara teori tidak bertentangan dengan definisi, hakikat dan contoh moorfologi bahasa Jepang.

\section{HASIL DAN BAHASAN}

Ada tiga istilah yang sering digunakan untuk menggambarkan interaksi antara morfologi dan fonologi. Interaksi antara morfologi dan fonologi tersebut di kalangan para linguis Amerika umumnya disebut dengan morfofonemik. Akan tetapi para linguis Eropa lebih menggandrungi istilah morfofonologi atau morfofonologi. Pada kajian ini, 
penulis mengggunakan istilah morfofonemik. Morfofonemik merupakan kata serapan dari bahasa Inggris morphophonemics atau sering juga disebut morphonemics. Definisi morfofonemik oleh para linguis dapat diartikan secara luas dan secara sempit.Secara luas morfofonemik mengacu pada analisis dan klasifikasi bentuk dan wujud penggambaran morfem, juga pada struktur bahasa yang menggambarkan pola fonologis dari morfem seperti penambahan, pengurangan, penggantian fonem atau perubahan tekanan. Dalam pengertian sempit, morfofonemik lebih dibatasi pada kajian mengenai bentuk perubahan yang terjadi pada morfem seperti perbedaan-perbedaan pada bentuk fonemik alternan-alternan morfem daripada struktur fonemik.

Dalam bahasa Jepang, morfofonemik disebut dengan igyoutai no koutai atau keitai on inron. Yanagisawa (1998:60) menyatakan definisi keitai on inron sebagai berikut : Keitairon no hitotsu. Keitai wo kouseisuru on in wo taishou toshi, keitairon wo hojosuru, onbin nado no on teki genshou wo kijutsusuru, taikeikasuru mono: keitai on inron termasuk dalam morfologi, dan merupakan suatu sistem yang menggambarkan peristiwa yang ditinjau dari bunyi pada morfem yang mengalami perubahan, dan sebagainya, yang termasuk dalam morfologi, dengan fonem yang menyusun/membentuk strukturnya sebagai objek.

Menurut Koizumi (1993:105-106) tipe morfofonemik bahasa Jepang yang terjadi pada morfem, antara lain:

1. Fuka 'penambahan bunyi'

Contoh: penambahan bunyi /er/,

$$
\begin{array}{ll}
\text { tsuku 'lekat' } & \rightarrow \text { tsukeru 'melekatkan } \\
\text { kowasu 'pecah, } & \rightarrow \text { kowaseru 'memecahkan' } \\
\text { yogosu 'kotor' } & \rightarrow \text { yogoseru 'mengotori' } \\
\text { penambahan bunyi /rare/, } \\
\text { homeru 'puji' } & \rightarrow \text { homerareru 'memuji' } \\
\text { ageru 'beri' } & \rightarrow \text { agerareru 'memberi' }
\end{array}
$$

2. Sakujo 'penghilangan bunyi'

Contoh: penghilangan bunyi /er/,

$$
\begin{aligned}
\text { sakeru 'mengembang' } & \rightarrow \text { saku 'kembang' } \\
\text { yomeru 'membaca' } & \rightarrow \text { yomu 'baca' } \\
\text { tsukeru 'membuat' } & \rightarrow \text { tsuku 'buat' }
\end{aligned}
$$

3. Chikau 'pergantian bunyi'

Contoh: atsumaru 'berkumpul' $\rightarrow$ atsumeru 'mengumpulkan'

$$
\text { hajimaru } \rightarrow \text { hajimeru }
$$

4. Zero setsuji 'imbuhan kosong'

Contoh: fuku 'bertiup' $\rightarrow$ fuku 'meniup'

Sedangkan menurut Suzuki (1975:80) menyatakan bahwa dalam bahasa Jepang, perubahan fonem dalam proses morfofonemik ada 6 , yaitu: 
a. Pelesapan Fonem (on in datsuraku)

Proses pelesapan fonem terjadi bila morfem dasar atau afiks melesap pada saat terjadi penggabungan fonem (Kridalaksana, 2007:195). Dalam bahasa Jepang peristiwa ini disebut on in datsuraku 'pelesapan fonem', yang jika dilihat dari penulisan kanjinya adalah 'on in' berarti fonem dan 'datsuraku' berarti gugur/ rontok/terpelanting keluar (Matsura, 1994:137 \& 768).

\section{Contoh:}

- prefiks kaku- 'setiap', jika ditambahkan pada dasar kata yang bermula dengan fonem $/ \mathrm{k} /$, misalnya -koku 'negara', maka bentuknya berubah menjadi /kak/, dengan melesapnya fonem /u/ menjadi /kakkoku/.

$$
\text { kaku-'setiap' + -koku'negara' } \rightarrow \text { kakkoku 'setiap negara' }
$$

- Ada juga pelesapan pada setiap huruf /n/ jika bertemu dengan huruf /b/, /m/, dan $/ \mathrm{p} /$ maka huruf $/ \mathrm{n} /$ akan melesap menjadi $/ \mathrm{m} /$.

$\begin{array}{ll}\text { Shinpai } & \rightarrow \text { Shimpai } \\ \text { Shinbun } & \rightarrow \text { Shimbun } \\ \text { Kanpai } & \rightarrow \text { Kampai } \\ \text { Senpai } & \rightarrow \text { Sequpai }\end{array}$

b. Penyingkatan fonem ( on in shukuyaku)

Proses penyingkatan fonem adalah gejala pemendekan bunyi fonemis sebagai akibat upaya penghematan atau ekonomisasi pengucapan (Kridalaksana, 1982:94). Penyingkatan ini dikenal dengan kontraksi. Dalam bahasa Jepang, perubahan ini disebut 'on in shukuyaku' jika dilihat dari huruf kanjinya 'on in' berarti fonem dan 'shukuyaku' berarti memendekkan / menyingkat (Matsuura, 1994:768 \& 972).

Wakai 'muda' + mono 'orang' $\quad \rightarrow \quad$ wakamono 'orang muda' Tokyo 'tokyo' + daigaku 'universitas' $\rightarrow \quad$ todai 'universitas Tokyo'

c. Perubahan fonem (on in koutai)

Proses perubahan fonem terjadi apabila pada saat proses penggabungan morfem dasar, fonem terakhir suku kata pertama adalah konsonan digabungkan dengan fonem awal suku kata kedua adalah vokal (Kridalaksana, 2007:194). Dalam bahasa Jepang proses perubahan ini disebut dengan 'on in koutai'. Jika dilihat dari kanjinya 'on in' berarti fonem dan 'koutai' berarti perubahan / pergantian (Matsuura, 1994:550 \& 768). Menurut Koizumi on in koutai terbagi 2 yaitu: 
1. Bouin koutai 'perubahan vokal', hal ini terjadi pada:

- Fukugou meishi 'nomina majemuk', yaitu: ketika dua kata digabungkan untuk menggabungkan kata majemuk, vokal terakhir dari kata yang pertama berubah. Contohnya:

$$
\begin{array}{lllll}
\text { sake- } & + & -y a & \rightarrow & \text { sakaya } \\
\text { ki- } & + & \text {-kage } & \rightarrow & \text { kokage } \\
\text { shiro- } & + & \text {-ito } & \rightarrow & \text { shiraito } \\
\text { aoi } & + & \text { sora } & \rightarrow & \text { aozora }
\end{array}
$$

Jadi, setiap fonem terakhir dari kata pertama yang diakhiri vokal, akan berubah menjadi vokal lain, jika digabungkan dengan kata lain akan menjadi kata majemuk, yaitu:

$\mathbf{e} \rightarrow \mathbf{a}, \mathbf{i} \rightarrow \mathbf{o}, \mathbf{o} \rightarrow \mathbf{a}$

- Keiyoushi teki 'adjektiva I', yaitu : ketika verba mendapat akhiran /-shii/, lalu menjadi adjektiva, maka vokal terakhir pangkal kata tersebut berubah. Contohnya:

$\begin{array}{lllll}\text { konomu- } & + & - \text { shii } & \rightarrow & \text { konomashii } \\ \text { akeru- } & + & - \text { shii } & \rightarrow & \text { akashii } \\ \text { kuiru- } & + & \text {-shii } & \rightarrow & \text { kuyashii }\end{array}$

Jadi, setiap kata yang mendapat akhiran /-shii/, maka fonem vokal terakhir dari kata tersebut berubah, yaitu:

$$
\mathbf{u} \rightarrow \mathbf{a}, \mathbf{e} \rightarrow \mathbf{a}, \mathbf{i} \rightarrow \mathbf{a}
$$

-Doushi teki 'Verba I', yaitu: ketika yang mendapat akhiran/sufiks/ setsubiji (/-su/ atau /-ru/) lalu menjadi verba baru maka vokal terakhir pangkal kata tersebut berubah.

Contohnya:

tobu- $\quad+\quad-s u \quad \rightarrow \quad$ tobasu

Jadi, jika kata kerja I (doushi) mendapat akhiran /-su/ atau /-ru/, maka fonem vokal terakhir dari kata tersebut berubah yaitu:

$$
\mathbf{u} \rightarrow \mathbf{a}
$$


2. Shiin koutai 'Perubahan konsonan', baik yang terjadi pada nomina majemuk, kata sifat I, maupun kata kerja I akan mengalami perubahan fonem seperti yang dinyatakan Nomura (1992:185) yaitu:

$$
\begin{array}{lll}
- & \mathbf{k} \rightarrow \mathbf{g} ; & / \text { kuni-/ }+/ \text {-kuni } / \rightarrow \text { /kuniguni/ } \\
- & \mathbf{s} / \mathbf{s h} \rightarrow \mathbf{z} / \mathbf{j} ; & / \text { /shima-/ }+/ \text {-shima/ } \rightarrow \text { /shimajima/ } \\
- & \mathbf{t} \rightarrow \mathbf{d} ; & / \text { toki-/ }+/ \text {-toki/ } \rightarrow / \text { tokidoki/ } \\
- & \mathbf{h} \rightarrow \mathbf{b} ; & \text { /hito-/ }+/ \text {-hito/ } \rightarrow / \text { hitobito/ }
\end{array}
$$

d. Pergeseran fonem (on in tenkan)

Pergeseran posisi fonem ini terjadi apabila komponen dari morfem dasar dan bagian dari afiks membentuk satu suku kata. Pergeseran bisa terjadi di depan, tengah dan belakang atau dengan pemecahan. Pergeseran ke belakang terjadi pada morfem dasar yang berakhiran pada konsonan yang diikuti oleh sufiks atau komponen akhir konfiks yang diawali vokal, sehingga konsonan tersebut menjadi bagian dari suku kata yang di belakang.

e. Penambahan fonem (on in tenka)

Dalam bahasa Jepang, proses ini disebut dengan on in tenka yang berarti pembubuhan atau penambahan fonem.Contohnya, prefiks /o/ ditambahkan pada dasar kata yang bermula dengan fonem /i/ misalnya /-inu/'anjing' maka akan muncul fonem /su/ setelah prefiks /o/ menjadi /osu-/.

$$
\text { /o-/ + /inu/ } \rightarrow \text { losuinu/ }
$$

f. Peleburan fonem (on in yuugou)

Dalam bahasa Jepang dikenal dengan on in yuиgou yang berarti peleburan atau peluluan fonem.

Contohnya pada proses pemajemukan/komposisi yaitu nomina + nomina $\rightarrow$ nomina. Fonem awal dari kata kedua yang diawali fonem $/ \mathrm{k} /$ akan berubah menjadi fonem /g/ setelah digabungkan dengan fonem akhir dari kata pertama.

$$
\text { /uel }+/ \text { ki/ } \rightarrow \text { /uwagi/ }
$$

\section{SIMPULAN DAN SARAN}

Proses morfofonemik dalam bahasa Jepang terbagi atas proses yang terjadi pada morfem dan proses yang terjadi pada perubahan fonemnya. Pada bahasa Jepang semua proses hampir sama seperti yang terjadi proses morfofonemik pada bahasa Indonesia. Tidak ada perbedaan dalam prosesnya. Sehingga dalam mempelajari morfologi bahasa Indonesia maka kita kemungkinan akan menjumpai hal yang sama pada bahasa Jepang, meskipun tidak semuanya sama. Dengan adanya penelitian ini diharapkan dapat menjadi acuan atau rujukan para pembelajar bahasa Jepang. Penelitian ini belum terlalu dikaji secara mendalam, sehingga diharapkan dapat dilakukan penelitian yang lebih mendalam dan luas lagi ke depannya. 
LINGUA, Vol. 14, No. 2, September 2017

p ISSN: 1979 9411; e ISSN: 2442 238X

Http://lingua.pusatbahasa.or.id; Email: presslingua@gmail.com

Center of Language and Culture Studies, Surakarta, Indonesia

Nasution, Suti H, Sari. 2017. Proses Morfofonemik dalam Bahasa Jepang.

Lingua (2017), 14(2): 259 266.

\section{DAFTAR PUSTAKA}

Keraf, Gorys. 1984. Tata Bahasa Indonesia. Flores: Nusa Indah

Kridalaksana, Harimurti. 1989. Pembentukan Kata dalam Bahasa Indonesia. Jakarta: Gramedia.

Kridalaksana, Harimurti. 2007. Kamus Linguistik. Jakarta: Gramedia

Koizumi, T. 1993. Gengogaku Nyuumon. Tokyo, Jepang: Kabushiki Kaisha.

Situmorang, Hamzon. 2010. Pengantar Linguistik Bahasa Jepang. Medan:USU Press

Sutedi, Dedi. 2003. Dasar-Dasar Linguistik Bahasa Jepang. Bandung: HumaioraUtama Press

Sari, Lelita Daulay. 2009. Skripsi: Analisis On In Koutai Bahasa Jepang Ditinjau Dari segi Morfofonemik. USU Repository

http://ja.wikipedia.org/wiki/.diunduh 01.04.2016 11.30AM

http://id.wikipedia.org/wiki/linguistik/diunduh01.04.2016 11.15AM 